\title{
Manejo anestésico del síndrome del opérculo torácico. Reporte de caso
}

\author{
Bonacina CF. $^{1,2}$, Ramírez ML. ${ }^{1}$ \\ 1 Hospital Ángel Cruz Padilla, Tucumán, Argentina. \\ 2 Sanatorio 9 de julio, Tucumán, Argentina.
}

Introducción: El síndrome del opérculo torácico (SOT) es causado por la compresión de las estructuras neurovasculares en su entrada torácica. Prevalencia variable de al menos 10 por 100.000 habitantes por año El SOT puede ser categorizado en tres subtipos distintos de acuerdo con el tipo de compresión: neurogénico ( $95 \%$ de los casos), venoso (4-5\%) y arterial (1\%). Predisponentes: anatómicos (costillas cervicales, primeras costillas anormales) y factores extrínsecos como el trauma o movimientos repetitivos.

Caso clínico: Paciente masculino, 57 años, ex jugador de vóley, con diagnóstico de SOTa de miembro superior derecho (MSD), prueba Ross positiva y motilidad conservada, EMG normal, angiografía de MSD que informó aneurisma subclavio y obstrucción trombotica (edema, palidez y ausencia de pulso), ingresó en plan de cirugía torácica y vascular por abordaje supraclavicular. Se resecó costilla cervical y torácica, se resolvió aneurisma con prótesis y se liberaron trombos. En las $24 \mathrm{~h}$ previas se administró pregabalina $75 \mathrm{mg}$ y paracetamol $1 \mathrm{~g}$ cada $12 \mathrm{~h}$. Se realizó anestesia general balanceada con bloqueo de plexo cervical superficial ecodirigido con $5 \mathrm{ml}$ de bupivacaina al $0,125 \%$, infusión de dexmedetomidina a $0,2 \mathrm{mcg} / \mathrm{kg} / \mathrm{min}$, monitoreo intraoperatorio estándar y con sistema clearsight, analgesia endovenosa postoperatoria con paracetamol $1 \mathrm{~g}$ ev. cada $8 \mathrm{~h}$. Se reanudó pregabalina vo a las $12 \mathrm{~h}$.

Complicaciones: Apertura de pleura apical. Pleurorrafia. Paciente con buena evolución clínica, a las 48 h se retiró tubo de tórax y alta a las $72 \mathrm{~h}$.

Discusión: Actualmente, no existen protocolos de manejo anestésico en el SOT por lo que se debería considerar la posibilidad de realizar normas de manejo estandarizado del mismo. Recomendamos la realización de accesos venosos de grueso calibre por el riego de hemorragia o embolia aérea, según el subtipo evaluar el uso o no de relajante neuromusculares, en caso de abordaje por otra vía considerar la posibilidad de realizar otro bloqueo analgésico (ESP o Paravertebral).

https://doi.org/10.25237/congresoclasa2019.56 